\section{Breathing through skin in a newborn mammal}

The exchange of oxygen and carbon dioxide through the skin does not occur in most mammals because they have high metabolic rates and diffusion through the skin is poor. But we have found that in the Julia Creek dunnart (Sminthopsis douglasi), a marsupial mouse with one of the smallest newborns of any mammal, gas exchange through the skin is the predominant form of $\mathrm{O}_{2}$ and $\mathrm{CO}_{2}$ transfer in the first days after birth.

These small newborns have lower $\mathrm{O}_{2}$ consumption than non-marsupial species ${ }^{1}$, and thermoregulation is not a problem because they develop in the thermoneutral environment of the maternal pouch. Further, because they are delivered at a very early stage of development ${ }^{2}$, the skin, which is hairless and rich in blood, provides a much smaller barrier to gas diffusion than in most newborn mammals.

A 70-kg human athlete can reach a level of maximal oxygen consumption $\left(V_{\mathrm{O}_{2}}\right)$ of up to $65 \mathrm{ml} \mathrm{kg}^{-1} \min ^{-1}\left(4,550 \mathrm{ml} \mathrm{min}{ }^{-1}\right)$. Such high values are possible because of a very large surface area for gas exchange in the lungs, estimated at about $70 \mathrm{~m}^{2}$ (ref. 3). In an adult human, the body surface could therefore never replace the lungs as a site of gas exchange because its total area is only about $2 \%$ of the minimal surface required. If the lungs were designed optimally ${ }^{4}$, the ratio between the pulmonary gas-exchange surface and $\mathrm{O}_{2}$ flux would be the minimum necessary for gas exchange. In humans, this value would be $70 \mathrm{~m}^{2}$ per $4,550 \mathrm{ml} \mathrm{min}{ }^{-1}$, or about $150 \mathrm{~cm}^{2}$ per $\mathrm{ml} \mathrm{O}_{2} \mathrm{~min}^{-1}$.

The Julia Creek dunnart is a small dasyurid marsupial from Australia ${ }^{5}$. After a

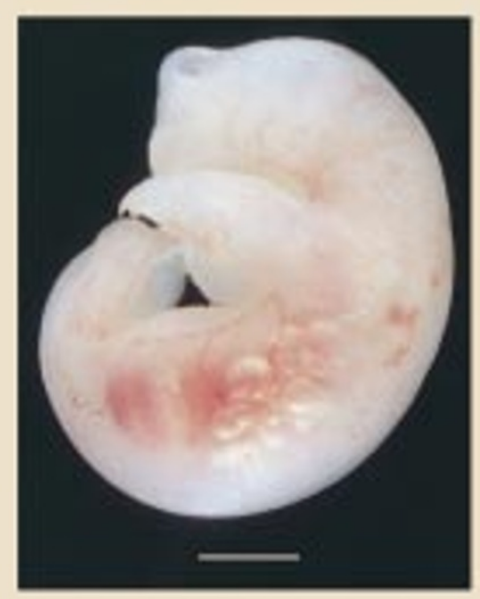

Figure 1 Pouch young of Sminthopsis douglasi at one day old. The lungs are visible as air sacs on each side of the heart. Despite the presence of ribs, no respiratory thoracic movements can be detected. Scale bar, $1 \mathrm{~mm}$.

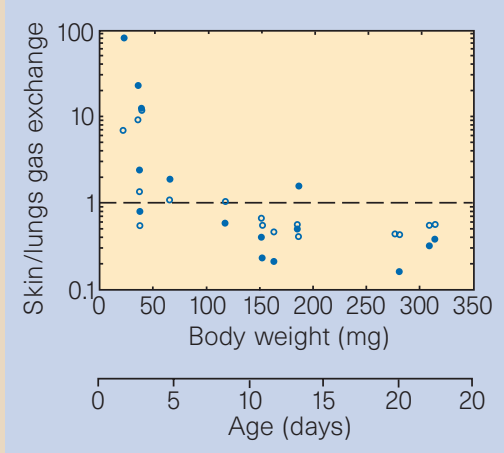

Figure 2 Ratio between skin and pulmonary gas exchange in the pouch young of $S$. douglasi. Values refer to oxygen consumption ( $V_{\mathrm{O}_{2}}$, filled symbols) and carbon dioxide production $\left(V_{\mathrm{CO}_{2}}\right.$, open symbols), measured at an ambient temperature of $36{ }^{\circ} \mathrm{C}$. The broken line indicates equal contributions of lungs and skin to total gas exchange.

gestation lasting about 13 days, the newborn is about $4 \mathrm{~mm}$ long and weighs around $17 \mathrm{mg}$, so it is one of the smallest newborn mammals known ${ }^{2}$. At birth, the skeleton is entirely cartilaginous and the internal organs are visible through the transparent skin. The lungs are represented by a small number of approximately spherical air sacs (Fig. 1). In the newborn dunnart and in individuals up to 21 days old, $V_{\mathrm{O}_{2}}$ averaged $18 \mathrm{ml} \mathrm{kg}^{-1} \mathrm{~min}^{-1}$, and the body surface area is estimated at about $7 \mathrm{~mm}^{2}$. The ratio between body surface area and $V_{\mathrm{O}_{2}}$ is therefore about $220 \mathrm{~cm}^{2}$ per $\mathrm{ml}$ $\mathrm{O}_{2} \min ^{-1}$, above the minimum value necessary for the skin to be an important site of gas exchange.

We measured separately, but simultaneously, the gaseous metabolism of lungs and skin in 22 pouch young from five litters during the first three weeks after birth. We sealed a mask made from a short length of polyethylene tube to the face of the animal, covering both mouth and nostrils, using a removable dental polyether material. The low mobility of the newborns ensured that the seal was maintained. The tube passed through a thin rubber stopper placed in the centre of a moist cylindrical chamber of volume $0.5-2 \mathrm{ml}$, completely separating the chamber into two compartments, one containing the animal and the other communicating with the airways.

A small quantity of air was injected into one compartment, and the absence of pressure transmission to the other indicated complete separation. The chamber was maintained at pouch temperature $\left(36^{\circ} \mathrm{C}\right)$ by a water bath. After temperature and humidity equilibration, the compartments were sealed for 5-15 min, depending on the animal's age. The compartments were then flushed with a constant airflow of $20 \mathrm{ml} \mathrm{min} \mathrm{ma}^{-1}$ and the gas was forced through a drying column before $\mathrm{O}_{2}$ and $\mathrm{CO}_{2}$ concentration were determined.

$V_{\mathrm{O}_{2}}$ and $V_{\mathrm{CO}_{2}}\left(\mathrm{CO}_{2}\right.$ production) were calculated from the time integral of the gas concentration curves ${ }^{6}$, multiplied by the flow and the time the chamber was sealed. At all ages, the skin's contribution to gas exchange was very marked. In the youngest animals, with body weight below $100 \mathrm{mg}$, gas exchange through the skin exceeded that through the lungs (Fig. 2). In the oldest individuals studied, which were 20 to 21 days of age with a body weight of about $290 \mathrm{mg}$, skin exchange was about one-third that of the lungs.

In animals two to three days old, spontaneous body movements did not appreciably expand the air sacs, and resulted in minimal changes in lung volume. These were calculated from the displacement of a drop of soapy solution in a microtube directly connected to the polyethylene tube sealed to the face of the animal, magnified by a microscope and displayed on a television screen by a video camera. These observations suggest that, in the Julia Creek dunnart during the early postnatal phases, pulmonary convection is highly inefficient. Sustaining oxygen demands through the skin allows these very small animals to be born before the respiratory apparatus is fully functional.

J. P. Mortola ${ }^{\star}$, P. B. Frappell $\dagger$, P. A. Woolley $\dagger$ ${ }^{\star}$ Department of Physiology, McGill University,

Montreal, Quebec, H3G 1Y6, Canada

$\dagger$ Department of Zoology, La Trobe University, Melbourne, Victoria 3083, Australia

e-mail: jacopo@physio.mcgill.ca

1. Baudinette, R. V., Gannon, B. J., Ryall, R. G. \& Frappell, P. B. Respir. Physiol. 72, 219-228 (1988)

2. Tyndale-Biscoe, H. \& Renfree, M. Reproductive Physiology of Marsupials (Cambridge Univ. Press, 1987).

3. Weibel, E. R. Morphometry of the Human Lung (Springer, Berlin, 1963).

4. Weibel, E. R. The Pathway for Oxygen: Structure and Function in the Mammalian Respiratory System (Harvard Univ. Press, Cambridge, Massachusetts, 1984).

5. Woolley, P. A. in The Mammals of Australia (ed. Strahan, R.) 134-135 (Reed, Chatswood, New South Wales, 1995)

6. Frappell, P. B., Blevin, H. A. \& Baudinette, R. V. J. Theor. Biol. 138, 479-494 (1989).

\section{Formation of ice Xll at different conditions}

The structural versatility of solid water has been reinforced by the identification of a metastable, crystalline phase called ice XII (ref. 1). It was obtained by cooling liquid water to $260 \mathrm{~K}$ at a pressure of $0.55 \mathrm{GPa}$. We have found ice XII in a completely different region of water's phase diagram and show that it can be formed under different conditions from those previously reported ${ }^{1}$.

We produced high-density amorphous ice (HDA) as described previously ${ }^{2,3}$ and 
observed crystalline impurities ${ }^{4}$ within the amorphous samples ${ }^{5}$. These impurities are metastable at a temperature of $77 \mathrm{~K}$ and ambient pressure. Since the discovery of ice XII, we have identified this crystalline contaminant. We used Rietveld refinement to confirm that the crystalline phase has a tetragonal unit cell with cell parameters $a=8.276 \pm 0.004 \AA$ and $c=4.027 \pm 0.004 \AA$, leading to a density, $\rho$, of $1.30 \mathrm{~g} \mathrm{~cm}^{-3}\left(\mathrm{H}_{2} \mathrm{O}\right)$ at $127 \mathrm{~K}$ and ambient pressure ( $\rho$ for HDA is $1.17 \mathrm{~g} \mathrm{~cm}^{-3}$ ).

A neutron powder-diffraction pattern of a fully deuterated sample is shown in Fig. 1a. The highest-symmetry space group meeting the reflection conditions is $I \overline{4} 2 \mathrm{~d}$. The calculated fractional coordinates and the intra- and intermolecular distances (see Supplementary Information) are in good agreement with previous data ${ }^{1}$. The structure of the high-density crystalline phase therefore corresponds to ice XII. In all our samples, the contaminating crystalline phases can be indexed to ice XII, with no other crystalline modifications being formed. Ice XII is metastable at ambient pressure, and transforms at temperatures above $135 \mathrm{~K}$ to cubic ice (Fig. 1a, inset).
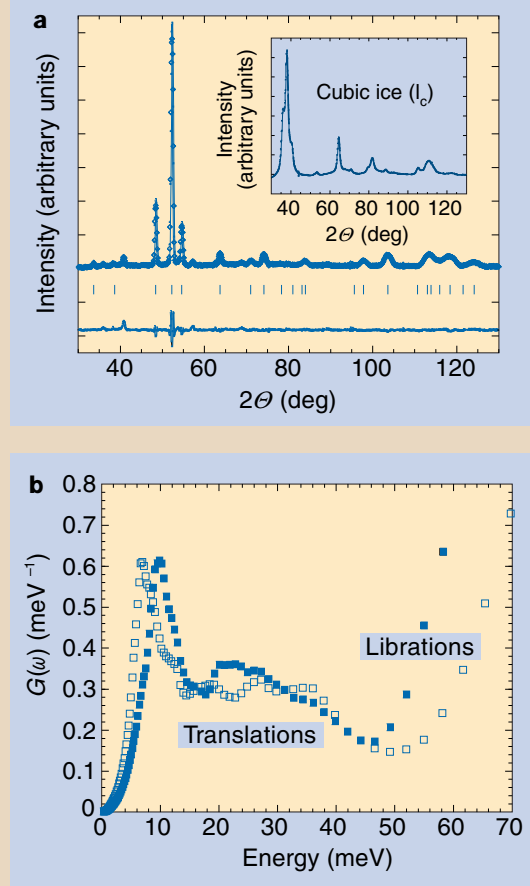

Figure 1 Elastic and inelastic neutron data. a, Measured and calculated neutron-diffraction patterns and the resulting difference profile of ice $\mathrm{Xl}$ at $127 \mathrm{~K}$ and ambient pressure. The data were collected at the high-flux beamline D2O at the Institut LaueLangevin, at a wavelength of $2.41 \AA$. Ticks indicate reflection positions. The inset shows the cubic phase $\left(I_{c}\right)$ obtained after the transformation from ice $X \| l$ to $I_{c}$. The shoulders on the $I_{c}$ reflections are due to stacking faults ${ }^{10}$. b, Frequency distribution $G(\omega)$ of protonated ice $\mathrm{Xl}$ (at $127 \mathrm{~K}$, filled symbols) and $I_{h}$ (at $240 \mathrm{~K}$, open symbols) measured at ambient pressure.

NATURE | VOL 397 | 25 FEBRUARY 1999 | www.nature.com
This conversion takes about $35 \mathrm{~min}$ at $145 \mathrm{~K}$.

To support our structural analysis, we determined the frequency distribution $G(\omega)$ of the external mode spectrum of ice XII in comparison with common hexagonal ice $\left(I_{h}\right)$, measured on fully protonated samples by inelastic neutron scattering (Fig. 1b). Although the overall shape of $G(\omega)$ for ice XII is similar to those of other highdensity ice phases, the details of the inelastic response are different ${ }^{6} . G(\omega)$ reflects the specific hydrogen-bond distortions that are unique to ice XII because it has seven- and eight-membered rings ${ }^{7}$. It therefore allows us to test hydrogen-bond models, such as the controversial idea ${ }^{6}$ that ice has two distinct hydrogen bonds.

We have tried to establish what it was in the production process that led to ice XII being produced. Its formation seems to be influenced neither by the shape nor by the material of the pressure cells. No distinct pressure dependence of the transition onsets for HDA and ice XII was observed, nor does the rate of compression favour one or the other of the two phases (rates from $1 \mathrm{GPa}$ per $100 \mathrm{~min}$ up to $1 \mathrm{Gpa}$ per $100 \mathrm{~s}$ were applied to ensure isothermal and quasiadiabatic conditions, in which heat is not lost or gained $\left.^{8}\right)$. Samples containing pure $\mathrm{D}_{2} \mathrm{O}$ (purity $99.9 \%$, resistivity $1 \mathrm{M} \Omega \mathrm{cm}$ ) and $\mathrm{H}_{2} \mathrm{O}$ (resistivity $18.2 \mathrm{M} \Omega \mathrm{cm}$ ) and isotopic mixtures give comparable results.

So we have been unsuccessful in identifying a route that would predictably allow us to separate the production of HDA from the production of ice XII. The relative amounts of HDA and ice XII are scattered more or less randomly, and both pure ice XII and pure HDA can be formed in some instances. Once HDA or ice XII has formed, it remains metastable up to a pressure of at least $2 \mathrm{GPa}$ at $77 \mathrm{~K}$.

These results indicate that water's phase diagram needs to be modified, particularly in the region that has been ascribed to HDA. It remains to be seen whether the region of metastability of ice XII previously reported ${ }^{1}$ is continuously connected to the region observed here. An extensive study of the structural features, dynamics and kinetics accompanying transitions involving ice XII might also lead to a better understanding of HDA at a fundamental, microscopic level. For example, it might be possible to model the microscopic structure of HDA by putting disorder into the ice XII network, as has been done successfully for low-density amorphous ices using the hexagonal ice I network ${ }^{9}$.

Michael Koza*, Helmut Schober $\dagger$,

Albert Tölle*, Franz Fujara ${ }^{\star}$,

Thomas Hansen $\dagger$

${ }^{\star}$ Fachbereich Physik, Universität Dortmund,

Otto-Hahn-Strasse 4, Dortmund 44221,

Germany

Æ๑) 1999 Macmillan Magazines Ltd e-mail: marek@e3.physik.uni-dortmund.de $\dagger$ Institut Laue-Langevin,

Avenue des Martyrs, BP 156,

38042 Grenoble, Cedex 9, France

1. Lobban, C., Finney, J. L. \& Kuhs, W. F. Nature 391, 268-270 (1998).

2. Mishima, O., Calvert, L. D. \& Whalley, E. Nature 310, 393-395 (1984).

3. Mishima, O., Calvert, L. D. \& Whalley, E. Nature 314, 76-78 (1985).

4. Bizid, A., Bosio, L., Defrain, A. \& Oumezzine, M. J. Chem. Phys. 87, 2225-2230 (1987)

5. Schober, H. et al. Physica B 241-243, 897-902 (1998).

6. Li, J. J. Chem. Phys. 105, 6733-6755 (1996).

7. O'Keeffe, M. Nature 392, 879 (1998).

8. Mishima, O. Nature 384, 546-549 (1996).

9. Dore, J. C. inWater Science Review (ed. Franks, F.) 3-92 (Cambridge Univ. Press, 1985).

10. Kuhs, W. F., Bliss, D. V. \& Finney, J. L. J. Physique 48, C-1631-C-1636 (1987).

Supplementary information is available on Nature's World-Wide Web site (http://www.nature.com) or as paper copy from the London editorial office of Nature.

\section{The bio-logic of facial geometry}

The final paragraph of the Letter by Perrett et al. ${ }^{1}$, on the effects of sexual dimorphism on facial attractiveness, remarks that "preferences would encourage a youthful, neotenous appearance in the species generally". But this conflicts with the semantics of 'masculine' and 'feminine' they use to construct their argument. Brennan's caricatures of Ronald Reagan ${ }^{2}$ also hint at this conflict. We have examined the logic of this argument and suggest that biological data might strengthen inferences made by Perrett et al. ${ }^{1}$.

We characterize the argument as semantic because masculine and feminine are used to refer to three distinct aspects of faces: the extent to which they reflect the action of sex hormones during growth; how they are perceived by the subjects queried; and their position on the shape continuum defined by the 174 feature points measured ${ }^{1}$.

We shall refer to these three aspects as biological, psychological and geometrical. The 'surprising ${ }^{3}$ nature of the observations rests on the unexamined identification of geometrical and biological or psychological sexuality: the idea that hormone-dependent sexual characteristics most notably ${ }^{4,5}$ advertise pathogen resistance ${ }^{6}$ (because the immunosupressive consequences of testosterone and oestrogen production ${ }^{7,8}$ are Zahavian handicaps ${ }^{9}$ ) leads Perrett et al. to expect their experimental subjects to prefer masculinized male and feminized female faces ${ }^{1}$. But this expectation evaporates if geometrical sexuality differs from biological sexuality for faces.

When their observations conflict with this expectation, Perrett et al. acknowledge that subjects' preferences "may reflect the effects of masculinity on perceived age" . That is, geometrical masculinity may be 